\title{
STUDI AWAL DISTRIBUSI TEMPERATUR ELEMEN BAHAN BAKAR REAKTOR CEPAT BERPENDINGIN GAS
}

\section{(PRELIMINARY STUDY OF THE ELEMENT TEMPERATURE DISTRIBUTION OF GAS-COOLED FAST REACTOR)}

\author{
Balya Lutviana Laila Saro, Fiber Monado, dan Menik Ariani \\ Fakultas Matematika dan Ilmu Pengetahuan Alam Universitas Sriwijaya \\ Jl. Palembang-Prabumulih KM. 32 Indralaya (OI) 30662 \\ Koresponding email: fibermonado@unsri.ac.id
}

\begin{abstract}
Abstrak
Tujuan dari penelitian ini adalah menganalisis desain reaktor berdasarkan aspek termalhidrolik dan melakukan perhitungan distribusi temperatur elemen bahan bakar pada kondisi tunak. Perhitungan dilakukan secara komputasi dengan menggunakan MATLAB (MATrix LABoratory). Metode yang digunakan ialah studi literatur dan perhitungan komputasi. Studi awal distribusi temperatur elemen menggunakan bahan bakar reaktor cepat berpendingin gas atau Gas cooled Fast Reactor (GFR). GFR ini didesain dengan bahan bakar uranium metal (U-10\%wtZr), pendingin Helium (He), kelongsong stainless steel 316 (SS316), dan daya $500 \mathrm{MWt}$. Untuk menghitung distribusi temperatur elemen bahan bakar digunakan dengan asumsi distribusi kerapatan daya di dalam bahan bakar merata ke segala arah baik untuk arah radial maupun aksial dan transfer panas berlangsung pada keadaan tunak untuk 1 kanal pendingin. Perhitungan distribusi temperatur elemen bahan bakar pada kondisi tunak dilakukan dengan menggunakan persamaan-persamaan yang diadaptasi dari Duderstadt dan Hamilton. Hasil penelitian ini menunjukan bahwa reaktor berada dalam batas aman dengan temperatur maksimum berada di bawah nilai titik leleh bahan bakar sehingga dari keadaan ini dapat menunjang keamanan pengoperasian reaktor.
\end{abstract}

Kata kunci: distribusi temperatur, elemen bahan bakar, GFR, MATLAB

\begin{abstract}
This study was aimed at analyzing the reactor design based on the thermal-hydraulic aspects and calculating the temperature distribution of the fuel elements in steady-state conditions. The computation was performed computationally using MATLAB (MATrix Laboratory). The methods used were literature study and computational calculations. The initial study of element temperature distribution was using the Gas-Cooled Fast Reactor (GFR). This GFR was designed with uranium metal fuel (U-10\% wtZr), Helium cooler (He), 316 stainless steel cladding (SS316), and $500 \mathrm{MWt}$ power. To calculate the temperature distribution of the fuel element, it took the assumption that the power density distribution in the fuel. The fuel was evenly distributed in all directions for both radial and axial directions and heat transfer took place at a steady state for 1 cooling channel. The calculation of the temperature distribution of the fuel elements under steady conditions was carried out using equations adapted from Duderstadt and Hamilton. The results of this study indicate that the reactor is within safe limits with the maximum temperature being below the melting point value of the fuel. From this state, it can support the safety of reactor operation.
\end{abstract}

Keywords: temperature distribution, fuel element, GFR, MATLAB 


\section{PENDAHULUAN}

Energi listrik merupakan salah satu kebutuhan yang penting bagi kehidupan manusia saat ini. Kebutuhan energi listrik di Indonesia meningkat seiring dengan bertambahnya jumlah penduduk. Kementerian Energi dan Sumber Daya Mineral menyatakan bahwa sumber energi listrik di Indonesia saat ini masih terfokus pada energi fosil yaitu minyak bumi, gas alam, dan batubara sehingga untuk beberapa tahun kedepan ketersediaan energi fosil akan semakin berkurang dan diperkirakan akan segera habis (BPPT, 2018).

Untuk mengatasi kebutuhan energi listrik yang semakin meningkat dan menipisnya persediaan bahan bakar fosil, diperlukan sumber energi alternatif. Salah satunya adalah pemanfaatan energi nuklir sebagai Pembangkit Listrik Tenaga Nuklir (PLTN). PLTN telah banyak dikembangkan di negara-negara maju seperti Amerika, Jepang, Prancis, dan beberapa negara lainnya. PLTN ini memiliki keunggulan yaitu biaya operasi murah, aman, dan tidak mencemari lingkungan. International Atomic Energy Agency (IAEA) menyatakan bahwa keseluruhan energi listrik yang dihasilkan reaktor nuklir sampai tahun 2019 telah mencapai $10 \%$ dari total energi listrik yang dipakai di dunia (IAEA, 2019).

Dalam perkembangan teknologi nuklir saat ini telah dan akan dikembangkan reaktor generasi maju yang inovatif dengan keselamatan tinggi, menggantikan reaktor (Gen III/Gen-III+) dengan reaktor (GenIV). Reaktor (Gen-IV) memiliki 6 jenis kandidat reaktor yang potensial dan layak dibangun pada tahun 2030 salah satunya yaitu Gas-cooled Fast Reactor (GFR). GFR merupakan pembangkit listrik yang menggunakan gas sebagai pendingin dengan siklus bahan bakar tertutup. Reaktor ini didesain memiliki temperatur keluaran sebesar $850^{\circ} \mathrm{C}$ yang memungkinkan untuk menghasilkan hidrogen atau memproses panas dengan efisiensi konversi yang tinggi (Suwoto \& Zuhair, 2012).

Hal pertama yang harus dilakukan sebelum membangun PLTN adalah proses perancangan teras. Perancangan ini bertujuan untuk melakukan studi atau analisis awal terhadap PLTN tersebut, di antaranya analisis neutronik, termal hidrolik, dan termodinamik. Analisis neutronik bertujuan untuk menghitung nilai fluks neutron dan pola distribusinya di dalam teras reaktor. Analisis termal hidrolik bertujuan untuk menghitung temperatur bahan bakar dari hasil reaksi fisi. Analisis termodinamik bertujuan untuk menghitung efesiensi dan daya listrik yang dapat dihasilkan dari PLTN tersebut (Drajat, 2011).

Penelitian ini difokuskan pada analisis termal hidrolik yang memiliki peran yang sangat penting dalam pengoperasian reaktor. 
Proses perpindahan panas hasil reaksi fisi dalam teras reaktor dibatasi oleh daya yang telah ditetapkan sesuai dengan batasan keselamatan. Parameter yang perlu diketahui adalah distribusi temperatur elemen bahan bakar pada kondisi tunak. Analisis dilakukan pada desain reaktor cepat tipe GFR dengan bahan bakar uranium metal (U-10\%wtZr), pendingin Helium (He), kelongsong stainless steel 316 (SS316), dan daya 500 MWt (Monita, 2015).

\section{METODE PENELITIAN}

Penelitian ini menggunakan laptop dengan sistem operasi windows 10 dan program MATLAB. Metode yang digunakan ialah studi literatur dan perhitungan komputasi. Data karakteristik teras dan elemen bahan bakar yang digunakan dalam perhitungan ditunjukkan pada Tabel 1 .

Untuk menghitung distribusi temperatur elemen bahan bakar maka akan digunakan beberapa asumsi yaitu: distribusi kerapatan

Tabel 1

Data Karakteristik Teras dan Elemen Bahan Bakar

\begin{tabular}{ll}
\hline \multicolumn{1}{c}{ Parameter } & \multicolumn{1}{c}{ Nilai } \\
\hline Desain teras reaktor (GFR) & $500 \mathrm{MWt}$ \\
Daya termal & $434,873 \mathrm{~W} / \mathrm{cm}^{3}$ \\
Kerapatan daya & Silinder-RZ \\
Geometri teras & $200 \mathrm{~cm}$ \\
Tinggi teras aktif & $210 \mathrm{~cm}$ \\
Diameter teras aktif & $50 \mathrm{~cm}$ \\
Tebal reflektor & $1,4 \mathrm{~cm}$ \\
Diameter pin pitch & $0,56437 \mathrm{~cm}$ \\
Jari-jari fuel & $0.04186 \mathrm{~cm}$ \\
Tebal cladding & $0,005 \mathrm{~cm}$ \\
Tebal gap & $380^{\circ} \mathrm{C}$ \\
Temperatur masukan & $330 \mathrm{~kg} / \mathrm{s}$ \\
Laju aliran massa pendingin & \\
Bahan bakar : Uranium metal (U-10wt $\% \mathrm{Zr})$ & $1233,85^{\circ} \mathrm{C}$ \\
Titik leleh & $0,4232 \mathrm{~W} / \mathrm{cm}^{\circ} \mathrm{C}$ \\
Konduktivitas panas & $14,103 \mathrm{~W} / \mathrm{cm}^{\circ} \mathrm{C}$ \\
Kelongsong : Stainless Stell $316(\mathrm{SS} 316)$ & \\
Konduktivitas panas & $0,5\left(\mathrm{~W} / \mathrm{cm}^{2}{ }^{\circ} \mathrm{C}\right)$ \\
Pendingin : Helium (He) & $5,193\left(\mathrm{~J} / \mathrm{kg}{ }^{\circ} \mathrm{C}\right)$ \\
Koefisien transfer panas &
\end{tabular}


daya di dalam bahan bakar merata ke segala arah baik untuk arah radial maupun aksial dan transfer panas berlangsung pada keadaan tunak untuk 1 kanal pendingin. Gambar 1 menampilkan penampang kanal pendingin untuk bentuk sel persegi.

Berdasarkan Gambar 1, perhitungan distribusi temperatur elemen bahan bakar pada kondisi tunak dilakukan dengan menggunakan persamaan-persamaan (1) s.d.

(7) (Duderstadt \& Hamilton, 1976).

$$
\nabla \bullet k \nabla T(r)=q^{\prime \prime \prime}(1)
$$

Untuk mendapatkan profil distribusi temperatur arah radial digunakan persamaan:

$$
\begin{aligned}
& q^{\prime}=\pi r_{F}^{2} q^{\prime \prime \prime} \\
& \Delta T_{F \cup E L}=T_{C L}-T_{F}=\frac{q^{\prime \prime \prime} r_{F}^{2}}{4 \bar{k}_{F}} \\
& \Delta T_{G A P}=T_{F}-T_{C}=\frac{q^{\prime \prime \prime} r_{F}}{2 h_{G}}
\end{aligned}
$$

$$
\begin{aligned}
& \Delta T_{C L A D}=T_{C}-T_{S}=\frac{q^{\prime \prime \prime} r_{F}}{2} \frac{t_{C}}{k_{C}} \\
& \Delta T_{C O O L}=T_{S}-T_{E}=\frac{q^{\prime \prime}}{h_{s}}=\frac{q^{\prime \prime \prime} r_{F}^{2}}{h_{s} 2\left(r_{F}+t_{C}\right)}
\end{aligned}
$$

Untuk mendapatkan profil distribusi temperatur arah aksial digunakan persamaan: $T_{F L}(z)=T_{i n}+\frac{q_{\max }^{\prime \prime \prime} \pi r_{F}^{2} H}{\pi w c_{p}}\left(1+\sin \left(\frac{\pi z}{H}\right)\right)_{(7)}$

Perhitungan dilakukan secara komputasi mengunakan MATLAB. Diagram alir program komputasi dapat ditunjukkan pada Gambar 2.

\section{HASIL DAN PEMBAHASAN}

Berdasarkan data karakteristik teras reaktor dan elemen bahan bakar pada Tabel 1, titik leleh uranium metal (U-10\%wtZr) diketahui sebesar $1233,85^{\circ} \mathrm{C}$. Temperatur

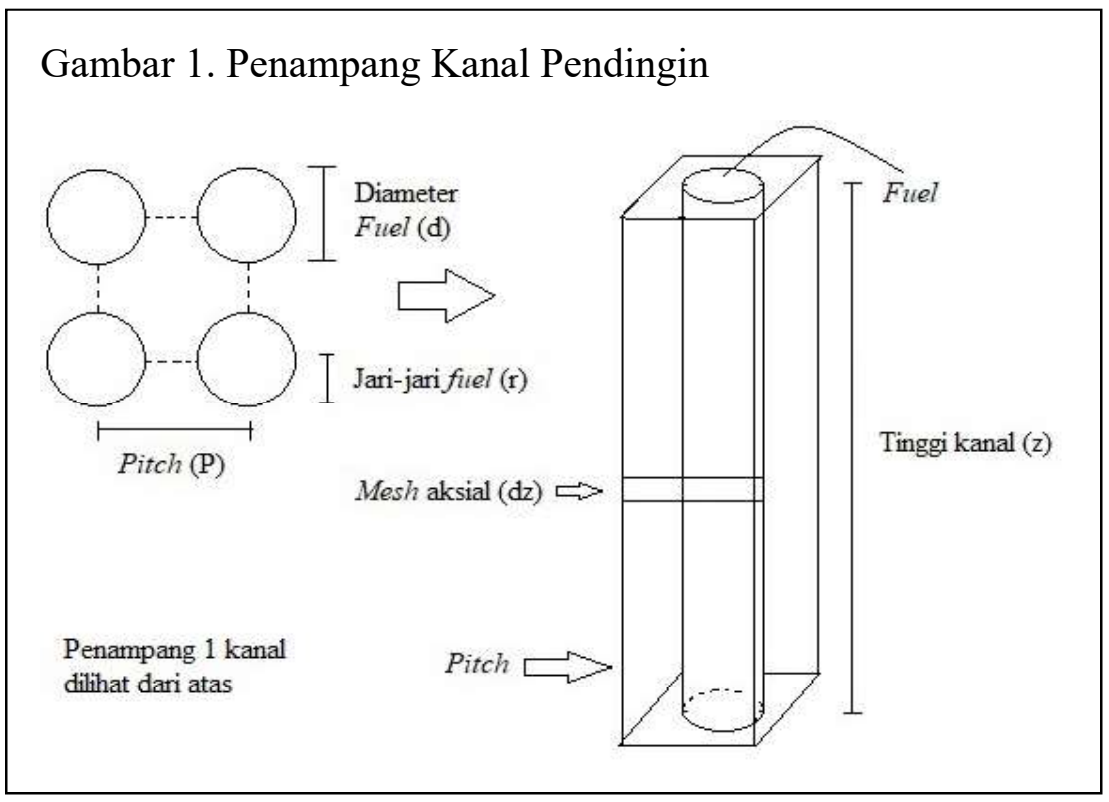




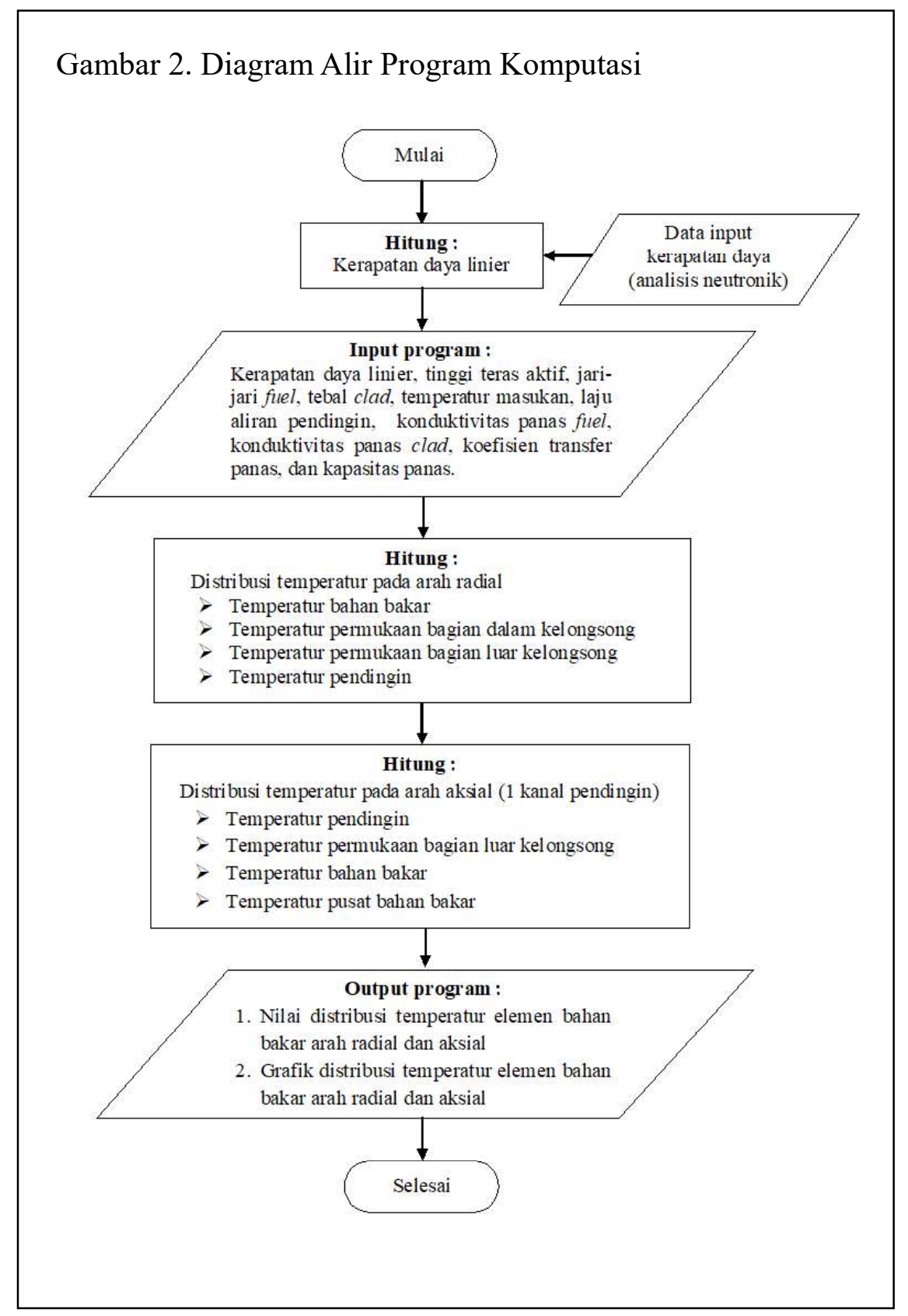

tersebut digunakan sebagai titik awal dari perhitungan sehingga dapat mengetahui distribusi temperatur bahan bakar, permukaan bagian dalam maupun luar kelongsong, dan pendingin. Data masukan kerapatan daya pada perhitungan distribusi temperatur arah radial sebesar $434,873 \mathrm{~W} / \mathrm{cm}^{3}$. Untuk menghitung distribusi temperatur arah radial digunakan persamaan (3), (4), (5) dan (6). Hasil perhitungan temperatur arah radial pada kondisi tunak ditunjukkan pada Gambar 3.

Gambar 3 menunjukkan penurunan temperatur secara bertahap dari pusat bahan bakar ke pendingin. Hal ini terjadi karena 
Gambar 3. Distribusi Temperatur dalam Pin Bahan Bakar Silinder

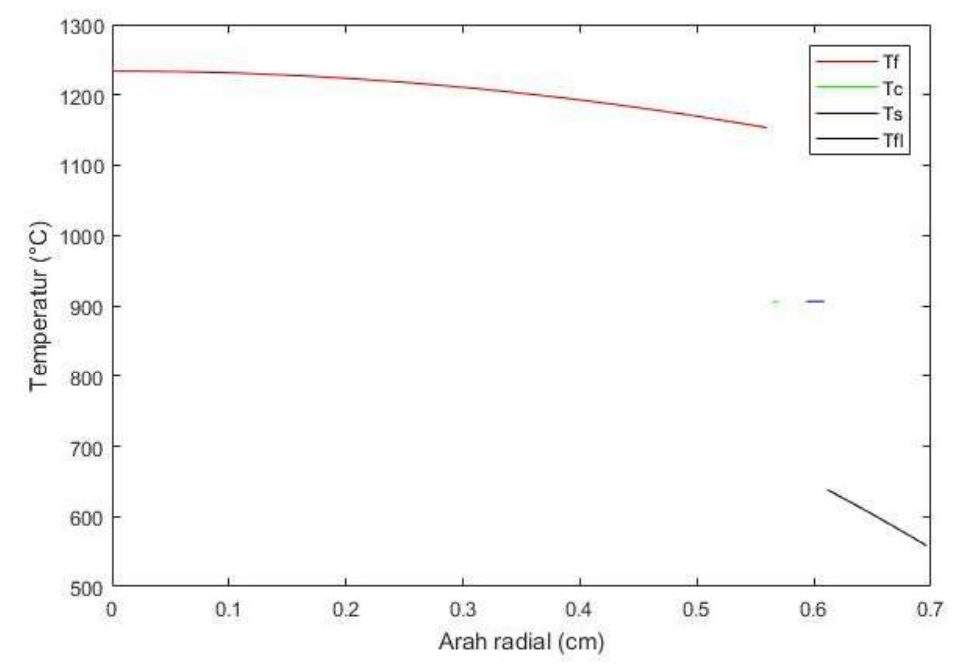

adanya proses perpindahan panas secara konduksi pada bahan bakar, konveksi pada gap, konduksi pada kelongsong, dan konveksi paksa pada pendingin. Nilai temperatur pada bahan bakar, permukaan bagian dalam maupun luar kelongsong, dan pendingin masing-masing sebesar 1153 , 904,4; 906,2; dan 558, $5^{\circ} \mathrm{C}$.

Perhitungan distribusi temperatur ketika melalui saluran pendingin digunakan persamaan (7). Data masukan kerapatan daya arah aksial sebesar 434,873 W/ $/ \mathrm{cm}^{3}$ dengan laju aliran pendingin sebesar $330 \mathrm{~kg} / \mathrm{s}$. Hasil perhitungan distribusi temperatur arah aksial pada satu kanal pendingin ditunjukkan pada Gambar 4.

Gambar 4 menunjukkan distribusi temperatur elemen bahan bakar pada saluran pendingin. Temperatur pendingin saat memasuki teras reaktor sebesar $380^{\circ} \mathrm{C}$, seiring dengan bertambahnya ketinggian teras reaktor, temperatur semakin meningkat. Hal ini terjadi karena panas yang diserap dari bahan bakar terakumulasi maksimal sehingga temperatur pendingin yang keluar dari teras reaktor mencapai $412,3^{\circ} \mathrm{C}$. Adapun untuk temperatur permukaan kelongsong, bahan bakar, dan pusat bahan bakar mengalami kenaikan yang stabil sampai titik maksimum masing-masing sebesar $624,6^{\circ} \mathrm{C}$; $870,4^{\circ} \mathrm{C}$; dan $952,2^{\circ} \mathrm{C}$. Kemudian turun pada temperatur tertentu. Bentuk grafiknya hiperbolik dan trennya mengikuti (Gambar 4) distribusi kerapatan daya di mana daya maksimum berada di titik pusat elemen bahan bakar. 


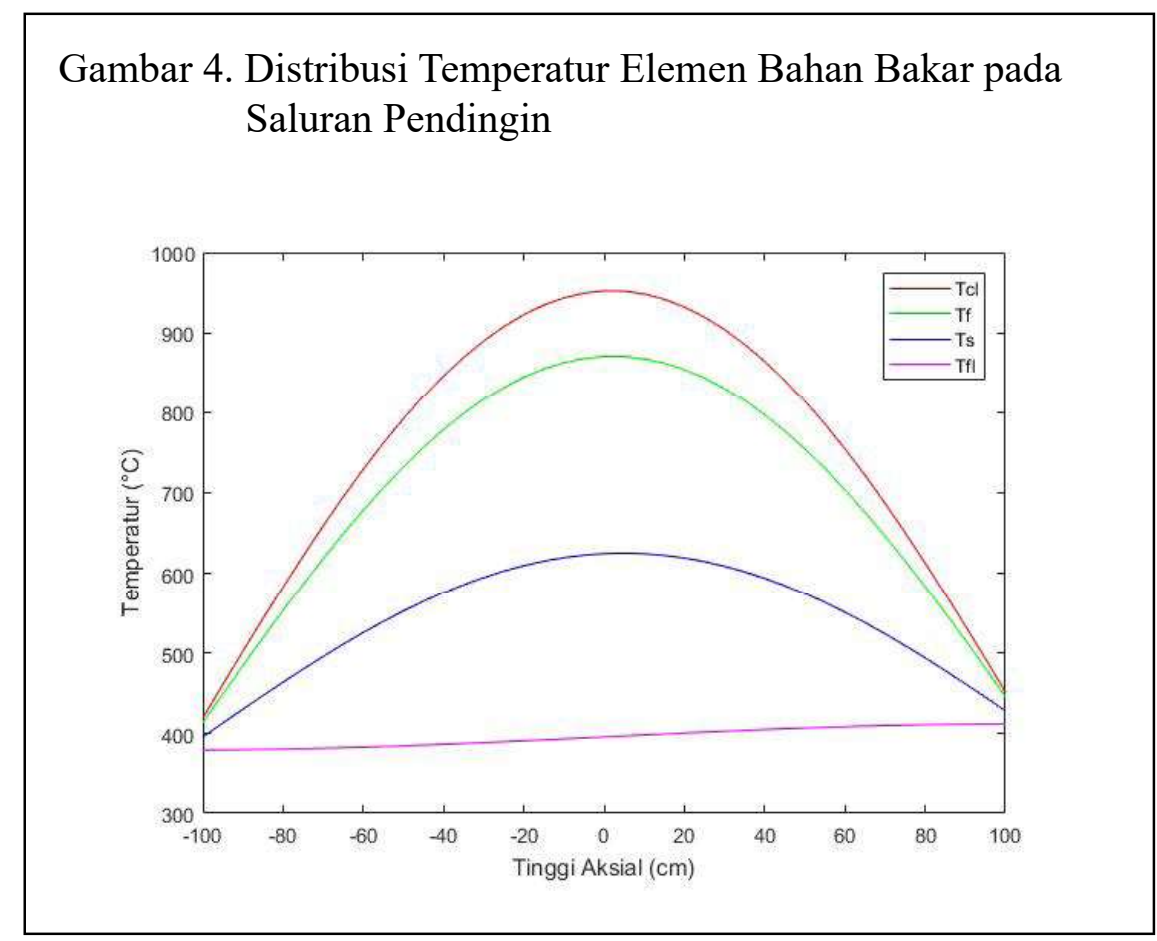

Dari hasil perhitungan distribusi temperatur elemen bahan bakar pada kondisi tunak yang ditunjukkan pada Gambar 3 dan Gambar 4 dapat diamati bahwa temperatur maksimum berada di bawah nilai titik leleh bahan bakar. Keadaan ini dapat menunjang keamanan pengoperasian reaktor $(\mathrm{BPTN}$, 2009).

\section{SIMPULAN}

Berdasarkan hasil dan pembahasan di atas dapat disimpulkan bahwa desain reaktor berada dalam batas aman dengan temperatur maksimum berada di bawah titik leleh bahan bakar sehingga dari keadaan ini dapat menunjang keamanan pengoperasian reaktor.

\section{DAFTAR PUSTAKA}

BPPT. (2018). Outlook energi Indonesia 2018: Energi berkelanjutan untuk transportasi darat. Tanggerang Selatan: Pusat Pengkajian Industri Proses dan Energi.

BPTN. (2009). Peraturan Kepala Badan Pengawas Tenaga Nuklir. Nomor 3 Tahun 2009 Tentang Batasan, Kondisi Operasi dan Prosedur Operasi Reaktor Daya. Tanggerang: BATAN.

Drajat, R. Z. (2011). Analisis termalhidrolik gas-cooled fast reactor (GCFR) (Skripsi tidak dipublikasikan). Fakultas Matematika dan Ilmu Pengetahuan Alam, Institut Teknologi Bandung, Bandung.

Duderstadt, J. J., \& Hamilton, L. J. (1976). Nuclear reactor analysis. New York: John Wiley \& Sons, Inc.

IAEA (2019). The Database on Nuclear Power Reactors. (online) tersedia http:// pris.iaea.org/PRIS/home.aspx. Diakses pada tanggal 28 Januari 2019, pukul 20.30 WIB. 
Jurnal Penelitian Saintek, Vol. 25, Nomor 2, 2020

Monita, N. (2015). Studi awal desain konseptual reaktor cepat tipe GFR dengan uranium metal sebagai input bahan bakar (Skripsi tidak diterbitkan). Fakultas Matematika dan Ilmu Pengetahuan Alam. Universitas Sriwijaya. Palembang.
Suwoto, \& Zuhair. (2012). Studi dan observasi awal kebutuhan data nuklir untuk reaktor generasi IV (Gen-IV). SIMETRI, Jurnal Ilmu Fisika Indonesia, l(1B), 18-25. 